\title{
NÓS E OS GREGOS
}

Maria Carolina Alves dos SANTOS ${ }^{1}$

- RESUMO: Este artigo responde afirmativamente à questão, vez por outra retomada, da efetiva contribuição que o estudo do pensamento político dos antigos gregos pode trazer ao debate dos problemas com que se defrontam as modernas sociedades democráticas.

- PALAVRAS-CHAVE: Democracia antiga e moderna; paradigma; polis; paidéia; logos; filosofia.

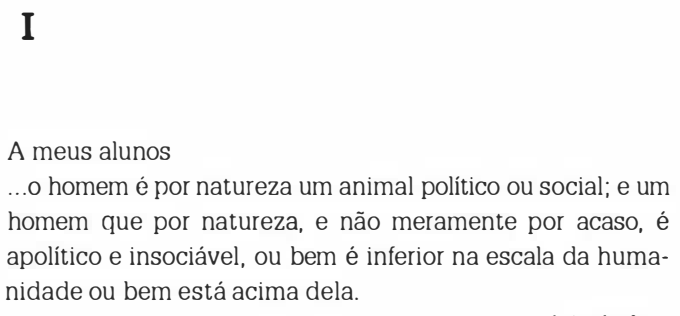

Aristóteles

Numa época de extraordinárias vitórias da inteligência nos domínios da ciência e da técnica, detecta-se a extrema inépcia do cidadão comum para participar do debate sobre as mais instigantes questões do seu tempo. Há um enorme contraste entre a sofisticação dos conhecimentos especializados e a complexidade dos problemas políticos da moderna sociedade democrática de um lado, de outro a ascendente indigência cultural do homem comum. Incapaz de desenvolver pensamentos autônomos e de proferir juízos independentes, ou mesmo de fazer uso das potencialidades projetivas do imaginário, ele imerge numa grande massa de indivíduos anônimos, desprovidos de arsenal crítico, de paradigmas, impossibilitados de avaliar corretamente as conseqüências de todo esse aparato técnico, científico e político para a vida das comunidades a que pertencem. Nas modernas democracias do Ocidente, como alerta

1. Departamento de Filosofia da Faculdacle de Filosofia e Ciências - UNESP - 17525-900 - Marília - SP. 
Horkheimer (1976, p. 6), o espetacular avanço da ciência e da técnica ameaça anular aquilo que a si mesmas propuseram como objeto precípuo, a própria idéia de homem.

Regidas pela lógica impessoal da racionalização do trabalho, a maioria dessas megassociedades democráticas ocidentais acaba por valorizar comportamentos tipificados, desestimulando perplexidades e tudo quanto possa representar obstáculo a uma perfeita planificação. O cidadão comum desenraiza-se da coisa pública, vive insulado, é apático, alienado do processo social: o espaço interior prevalece sobre a esfera coletiva do espaço urbano. Ao destituir-se dos ideais comunitários, sua natureza, essencialmente política, se perverte.

A democracia só pode funcionar bem, de acordo com uma teoria moderna de caráter elitista, se estiver fundamentada sobre o princípio da separação total entre lideranças e liderados, se gerida por uma oligarquia de políticos e burocratas profissionais, se limitar a participação popular na vida pública. Sob essa ótica, a apatia política do povo torna-se positiva e benéfica. A apatia enquanto falta de sentimento, insensibilidade, ausência de perplexidade é o avesso do espírito comunitário. É, no entanto, considerada um bem político nessa concepção de democracia que se empenha na formação de uma elite, destinada a tomar decisões no lugar da enorme massa passiva, cuja participação política se reduz ao ato de votar em eventuais eleições. E mesmo assim, observa Finley, ${ }^{2}$ a maior parte deles nem se dá ao trabalho de exercer esse estimado direito.

Para que o homem atual possa decifrar o enigmático fenômeno que a moderna democracia representa, as profundas mudanças que desencadeou em sua maneira de experienciar o espaço coletivo e em sua própria natureza, uma consideração de caráter histórico pode ser esclarecedora: a experiência política da Grécia antiga.

Pensar retrospectivamente a significação da extraordinária concepção q'ie os gregos têm sobre o lugar do indivíduo na sociedade, como integrante de uma comunidade de iguais (os politai), decidindo sobre questões comuns em debates organizados, buscando um modo de existir mais digno, tornando-se por isso criadores da política e da teoria política, é tomar de empréstimo da História um vigoroso paradigma (paradeigma), rico de estímulos a uma especulação portadora de perspectivas novas. Afirma Schuhl, citado por Arendt (1972, p. 11):

... a experiência politica das cidades gregas assume para nós a significação de u m paradigma: as reflexões que elas inspiram em seus pensadores têm um valor ao mesmo tempo explicativo e formativo. Analisando lucidamente sua época, eles nos levam a compreender a nossa. ${ }^{3}$

2. Finley \& Bailey (1992, p. 17-8). Segundo Finley, a grande maioria dos homens ocidentais se considera, atualmente, democrata. Isso é possivel porque houve uma redução radical da participação popular no processo politico em relação à concepção original da democracia grega: as decisões são tomadas pelos líderes politicos e não pelo voto popular.

3. "Criar uma civilização digna do que há de melhor no homem, eis em que sentido é preciso imitá-los, não copiando-os servilmente, mas colocando-nos em estado de preparar as grandes sinteses, que serão para o homem do século XX o que o aticismo foi para o século V. Esse é o dom mais raro que a Hélade nos oferece, o mais precioso a colher e meditar, em meio às dificuldades sem número em que se debate nossa época" (Arendt, 1972. 
Muitos pensadores da nossa época, procurando divisar, nos horizontes da temporalidade, meios de transformação das comunidades em que vivem, tomaram os gregos como modelo. Não para tentar a mera transposição da experiência de uma sociedade pequena e homogênea, onde todos se conheciam, para sociedades tecnologizadas e complexas, onde o interlocutor cotidiano mais freqüente é uma máquina, não um homem. Buscam assim a plena restauração dessa herança política, cujo poder (krátos) marcou para sempre a fisionomia do povo (demos) do Ocidente: visam recuperar a memória dessa absoluta novidade que foi, para a cultura de então, o surgimento da Democracia e da Filosofia.

Toda vez que eclode a crise de uma tradição vital - tal como a que a sociedade contemporânea ora atravessa - é fundamental um retorno ao princípio em sentido pleno (arkhé), à fonte mesma de onde brota sua essência, para que se alcance uma visão mais ampla das questões cruciais com que se defronta, necessánia à formulação de soluções mais plausíveis para elas. ${ }^{4}$ Segundo Leo Strauss, a crise do pensamento político moderno só será entendida mediante a compreensão de sua ruptura com a tradição, a filosofia política clássica, à qual está profundamente vinculada. ${ }^{5}$ É, pois, restaurando a trama originária do fragmentado tecido da nossa cultura, urdindo pacientemente seus liames com a tradição, que poderá surgir algo qualitativamente

p. 12-3). Cf. também Bréhier, s.d., p. 23-4; afirma Bréhier que, meditando sobre o exemplo dos gregos, é possivel saber melhor o que somos e o que queremos: "Nossa época é uma cruzada de caminhos, de um lado uma civilização técnica cujas descobertas nos dão potentes meios de agir sobre a natureza, de modificar à vontade os fenômenos da vida e da sociedade. Mas a técnica, diz ele, não nos indica os fins dessa ação. Vemos uma civilização técnica acompanhada de uma profunda incerteza sobre o fim das ações humanas. Do outro lado, vemos uma civilização humanista, menos atenta aos resultados técnicos que ao desenvolvimento do espírito, mais sensivel às descobertas que às suas aplicações, à perfeição dos conhecimentos que à sua extensão, preferindo o equilíbrio ao poder. É a civilização que os gregos introduziram no mundo: 'A cidade perfeita, diz um de seus filósofos, é feita não somente para viver, mas para viver bem', isto é, não para a satisfação das necessidades materiais e fisiológicas, mas para uma vida conforme a dignidade humana. Entre esses dois tipos de civilização nós somos talvez forçados a escolher; e é um dos grandes problemas da nossa época saber se, nas necessidades que oprimem nossas sociedacles, nós chegaremos a manter intacta a herança grega, que, sozinha, nos permitiu a nós todos, mesmo àqueles que a ignoram, viver uma vida de homem"

4. "... a nossa história - na sua mais profunda unidade - assim que deixa os limites de um povo particular e nos inscreve como membros num vasto circulo de povos, "começa" com os Gregos ... "Começo" não quer dizer aqui início temporal apenas, mas ainda arkhé, origem ou fonte espiritual, a que sempre se tem que regressar para encontrar orientação. É este o motivo por que, no decurso de nossa história, voltamos constantemente à Grécia. Ora, este retorno à Grécia, esta espontânea renovação da sua influência, não significa que lhe tenhamos conferido, pela sua grandeza espiritual, uma autoridade imutável, fixa, independente do nosso destino. O fundamento do nosso regresso reside nas nossas próprias necessidades vitais, por mais variadas que elas sejam através da História" (Jaeger, s.d., p. 6).

5. Finley \& Bailey, L'Héritage de La Grèce et de Rome, 1992, p. 9. Leo Strauss desenvolve, em suas obras, uma crítica à democracia liberal baseada não só no conhecimento de obras fundadoras da teoria democrática moderna, como também na reatualização de um problema considerado resolvido, da superioridade do pensamento moderno sobre o pensamento clássico. A querela entre os antigos e modernos é a chave da compreensão da dificuldade em que o mundo e a filosofia ocidental se encontram. Com efeito, a falência da filosofia moderna em resolver o problema político e a falência correlativa da democracia moderna em realizar o ideal democrático se devem ao rompimento dos primeiros filósofos politicos da modernidade com a tradição politica clássica na qual eles ainda se situavam. 
diferente, uma concepção política inovadora, da mesma envergadura que foi para os séculos VIII e VII a invenção da polis (Vernant, 1981, p. 34).

\section{II}

A Grécia é o locus social-histórico onde foram criadas a democracia e a filosofia, e onde se encontram, por conseguinte, nossas próprias origens. Na medida em que as potencialidades dessa criação não estejam esgotadas - e estou profundamente convencido de que não estão - a Grécia é para nós um gérmen.

Castoriadis

A criação, na antiga Grécia, de um espaço de reunião a céu aberto, no centro da comunidade, não apenas geográfico porém cívico, dá início à política enquanto atividade humana específica. Representa uma grande conquista para a civilização ocidental o acordo entre os homens de que, doravante, as resoluções de interesse geral apenas poderiam ser tomadas ao termo de um amplo debate público na ágora (palavra correspondente ao verbo eigeirein, que significa "reunir"). Os problemas da coletividade, antes geridos pelo rei ou pelos melhores (oi anistoi), passam a ser discutidos livremente por todos os iguais (oi homoioi). A característica essencial dessa nova forma de conduzir as questões pertinentes a todos é a participação pessoal e direta dos cidadãos: os homens são a cidade (andres gar polis), afirma Tucídides (1990, v. 6, p. 77).

O nascimento da polis empresta ao grego uma segunda vida, que se sobrepõe ao âmbito da esfera pessoal e privada, o bios politikós. Reunidos em assembléia (écclesia), animados pelo espírito de competição (âgon), persuadem-se, deliberam, decidem em conjunto sobre o que é comum (koínon). Esse grande comício ao ar livre era franqueado a todos os cidadãos que quisessem comparecer para dar a palavra decisiva sobre assuntos relativos a atividades governamentais: guerra ou paz, finanças, tratados, legislação, obras públicas. Na votação final, naturalmente preparadapor um período de intensa discussão - nas lojas e tavernas, na praça, em casa com os familiares - cada um tinha o direito de tomar a palavra e opinar, ao que se dá o nome de isegoria ou de democracia. O logos é soberano na condução da vida política assim instituída, instaura uma ordem (kósmos) ao estabelecer leis básicas que dão coesão interna ao grupo. Nesse novo modo de tratar a coisa pública, discurso (léxis) e ação (práxis) possuem a mesma categoria.

Calcada sobre esse modelo de vida política, a democracia grega propõe, como finalidade última, não só satisfazer às necessidades materiais dos cidadãos, mas possibilitar-lhes também uma vida bela, bem ordenada (eu zen), mais conforme à 
dignidade humana. ${ }^{6}$ Ela se exerceu de modo estável e pleno em Atenas, que, por quase duzentos anos, foi a mais próspera, a mais poderosa, a mais rica culturalmente de todas as poleis do mundo grego. Atenas representa, formal e historicamente, a mais perfeita realização da polis, a que é política por excelência. ${ }^{7}$ É um paradigma cujos cânones se alicerçam sobre uma paidéia voltada à construção de um elevado tipo de homem, pelo desenvolvimento máximo de suas potencialidades. Se o homem é por natureza um ser político, a formação verdadeira consiste em prepará-lo para ser um cidadão completo, realizado, inteiramente integrado na vida da comunidade.

A formação do cidadão grego era dispensada pela própria polis. Eram agentes naturais de desenvolvimento das virtudes morais, da responsabilidade cívica, da identificação madura com a comunidade, com suas tradições e valores, instituições fundamentais como a família, o ginásio e, sobretudo, as assembléias. Nessas ocasiões, quando se tomava contato com as questões políticas candentes, discutindo e julgando e decidindo, é que o padrão ético e intelectual do polites se elevava. A polis, por assim dizer, abarcava todos os domínios da existência humana, não por submeter de modo alienante o indivíduo à coletividade, e sim pela exata coincidência de interesses que havia entre ambos. De acordo com Ehrenberg:

... Em principio e mesmo em uma realidade onde nada era naturalmente perfeito, as forças se equilibravam: o homem era um zôon politikon, isto é, um ser vivo inserido na polis: a polis era a comunidade de cidadãos (koinônia tôn politôn). Aquilo que, de um lado, era ainda sacrifício espontâneo, era já coerç:ão estatal de outro: os limites se desfaziam e, se inúmeras leis intervinham profundamente na vida privada dos cidadãos, a própria sociedade dos cidadãos as instituiu. (1970, p. 156-7)

Fundamentada sobre essa concepção inteiramente original da relação entre o indivíduo e poder, a polis propiciou o solo adequado para que a liberdade pudesse florescer. Nenhum outro Estado conseguiu instituir tão bem quanto este o compromisso entre liberdade e poder, afirma Arendt, porque soube compreender a estreita interdependência de natureza entre liberdade e política, ou a inviabilidade de qualquer

6. Comenta o autor que essa realização foi contestada por dois eminentes filósofos gregos, mas em nome de uma autêntica forma de polis, diversamente caracterizada e proposta como um ideal. 'Trata-se de Platão e Aristóteles, que criticaram severamente a democracia e recusavam a identificação do demos com a comunidade (Cavalcante, 1982, p. 19, nota 18). Nos tempos modernos, ela tem sido confusamente avaliada enquanto realização da democracia, liminarmente comprometida no mundo grego pela escravatura e pela exclusão das mulheres, restrições eliminadas nas cartas de prıncípios que fundam as democracias modernas. A confusão está, afirma Cavalcante, precisamente nessa critica retrospectiva, que consagra uma superioridade do moderno principio democrático, entretanto, imperfeitamente realizado, nos melhores casos, na forma de Estado (as melhores democracias sabidamente sempre se sustentaram sobre a exclusão clas classes trabalhadoras e sobre a opressão de povos colonizados e semicolonizados). "Num mal discriminado confronto se projeta como uma sombra, sobre o que foi efetivamente realizado, a irrealização do nosso principio. E se obscurece a própria idéia de realização" (Cavalcante, 1982, p. 19, nota 19).

7. Finley \& Bailey, L'heritage dela Grèce et de Rome, 1992, p. 45. Atenas proporciona um valioso material de estudo de como a liderança política e a participação popular podem coexistir com sucesso por um longo peńodo de tempo. 
ação política sem a efetiva presença da liberdade. ${ }^{8}$ Mais que um atributo do pensamento e da vontade, a liberdade é então considerada uma qualidade própria da prática política. Por oposição ao homem moderno, o grego não valorizava a possibilidade de desenvolver atividades particulares sem interferência do Estado, porque resultariam na atomização dos indivíduos. O essencial para ele era poder interagir intensamente com os concidadãos a propósito da coisa pública, instaurando, assim, a solidariedade social: o indivíduo só poderia ser livre no interior do Estado e não isolado dele (Coulanges, 1885, p. 268-9). ${ }^{9}$

A liberdade é, pois, a característica determinante da democracia, enquanto condição indispensável para o seu exercício. E é em virtude dos contatos e trocas estabelecidos na ágora, espaço onde cada qual coloca livre e contraditoriamente seu ponto de vista, que se cria a atmosfera propícia à perplexidade, à interrogação incessante, à busca de definições mais precisas e coerentes. Do advento da polis, e, mais especificamente, da democracia, surge uma atividade racional inovadora. A racionalidade e a estrutura social próprias à cidade grega são duas ordens de fenômeno indissoluvelmente ligadas, e não por acaso: a razão manifestou-se primeiramente na Grécia, com seus conceitos e princípios, porque a experiência social, fundamentada na liberdade de argumentar, sobre o que seria mais justo e mais favorável ao bem-estar comum, assim o permitiu, afirma Vernant (1977). Da perfeita conjunção, nesse momento da história da civilização ocidental, entre as normas do jogo político e do jogo intelectual, sob o patrocínio da democracia, pode nascer a filosofia. ${ }^{10}$

8. O campo em que a liberdade sempre foi conhecida, não como um problema, é claro, mas como um fato da vida cotidiana, é o âmbito da política. E mesmo hoje em dia, quer saibamos ou não, devemos ter sempre em mente, ao falarmos do problema da liberdade, o problema da política e o fato de o homem ser dotado com o dom da ação; pois ação e política, entre todas as capacidades e potencialidades da vida humana, são as únicas coisas que não poderiamos sequer conceber sem ao menos admitir a existência da liberdade, e é difícil tocar em um problema político particular sem, implícita ou explicitamente, tocar em um problema de liberdade humana. A liberdade, além disso, não é apenas um dos inúmeros problemas e fenômenos da esfera política propriamente dita, tais como a justiça, o poder ou a igualdade; a liberdade, que só raramente - em épocas de crise ou de revolução - se torna alvo direto da ação politica, é na verdade o motivo por que os homens convivem politicamente organizados. Sem ela, a vida política como tal seria destituida de significado. A razão de ser da política é a liberdade, e seu domínio de experiência é a ação (Arendt, 1972, p. 1-2).

9. De acordo com Coulanges (1885), a liberdade tal como é entendida pelos antigos, é inteiramente estranha à compreensão e à sensibilidade dos modernos. Os antigos não conheceram a liberdade individual, estavam em tudo submissos à cidade onipotente: não se permitia que ninguém permanecesse indiferente aos seus interesses.

10. "Não é certamente pelo fato do acaso que a razão surgiu na Grécia como em conseqüência dessa forma tão original de instituição politica que chamamos Cidade. Com a Cidade, e pela primeira vez na história do homem, o grupo humano considera que seus negócios comuns não podem ser regrados, as decisões de interesse geral tomadas, senão ao termo de um debate público e contraditório, aberto a todos e onde os discursos argumentados se opõem uns aos outros. Se o pensamento racional apareceu nas cidades gregas da Ásia Menor como Mileto, é porque as regras do jogo político nos quadros da cidade - o debate público argumentado, livremente contraditório - se tornaram também a regra do jogo intelectual. Isso implica, de acordo com nossa visão, que para o racionalismo a noção de debate, de argumentação contraditória, constitui uma condição fundamental" (Vernant, 1977, p. 100-1). De acordo com Wolff, um dos méritos da Atenas clássica foi o de inventar a filosofia e a democracia, porém, não ao mesmo tempo, e nem sob a mesma relação. Não ao mesmo tempo, porque a democracia ateniense nasce com as reformas de Clistenes, no início do século $\mathrm{V}$ e o desmoramento do império, ao fim do século $\mathrm{V}$, marca o fim de 
Eu não vejo para que serviria a filosofia clássica à nossa época, se não para desencadear uma ação intempestiva contra esse tempo, portanto, também sobre esse tempo e, espero, em proveito de um tempo a vir.

Nietzsche

Perder de vista o paradigma grego desse modo singular de ordenar as relações políticas entre os homens, em coletividades independentes e unitárias, referencial de todos os povos da superfície do globo, significa declinar da via de acesso privilegiada à essência do político. A palavra política, em todas as línguas européias, é derivada de polis, razão pela qual toda reflexão sobre questões dessa natureza evoca a experiência desse povo que, como nenhum outro, definiu com tanta clareza essa forma de atividade humana e atribuiu, por isso mesmo, tamanha dignidade ao seu âmbito. De acordo com Strauss:

... Os gregos não vêem as coisas políticas do exterior como espectadores da vida política. Eles falam a linguagem dos cidadãos e dos homens políticos: ... sua filosofia política é global: é ao mesmo tempo uma teoria politica e um savoir-faire político... Comparado à filosofia política clássica, todo pensamento político ulterior, quaisquer que sejam seus méritos, e em particular o pensamento político moderno, tem um caráter derivado. Isso significa que nas épocas seguintes afastamo-nos das questões simples e primeiras. (1959, p. 33)

Se o homem contemporâneo, nas insatisfatórias condições de existência em que se encontra, tem urgência de repolitizar sua vida pessoal, de reavaliar as condições de convivência e de conquistar novos espaços de liberdade, é fundamental reconduzir o seu pensar em direção à filosofia política grega. Retomar as questões simples e primeiras que foram objeto de exaustiva investigação pelos pensadores antigos, e que não foram suficientemente exploradas por nós - a autonomia do político, a primazia da liberdade, a origem do poder, os fins do indivíduo e do corpo social, as necessidades coletivas e a divisão do trabalho - certamente projetará nova luz sobre os mecanismos

sua idade de ouro; enquanto a idade de ouro da filosofia começa no fim da idade de ouro da democracia (em 399). Isso não significa que depois de 404 a.C. não tenha havido mais democracia em Atenas, mas não se teve mais a mesma fé no regime. E o desnivel entre filosofia e democracia não é apenas temporal. É como se houvesse desde o início um imenso mal-entendido. A democracia do século $\mathrm{V}$, inteiramente voltada para a política, se vale dos velhos princípios da moral pragmática - a dos sete sábios - despreza as vãs pesquisas sobre a physis e sobre o ser; e, por outro lado, nenhum pré-socrático se ocupa da política, não há nenhum democrata entre os grandes filósofos atenienses (nem Platão nem Aristóteles propõe um Estado democrático em suas reflexões). Isso não quer dizer que a filosofia não tenha nascido deste desenvolvimento imenso da discussão pública, da liberação da palavra política que a democracia permitiu. A filosofia é filha da democracia, mas é certamente uma criança tardia e rebelde: nascida do logos e da democracia, teve sem dúvida um destino edipiano (Wolff, 1983, p. 7-9). 
falidos da sociedade democrática atual, que cerceiam sua plena realização em termos de legitimidade, estabilidade, solidariedade e igualdade de oportunidades.

Numa sociedade com acentuadas características liberais como a nossa, erigida sobre valores destinados a garantir as liberdades individuais a todo custo, há forte resistência contra políticas voltadas para o bem-estar comum. A supervalorização da individualidade é incompatível com a instauração de um ethos mais comunitário. Somente circunstâncias poderosas e inquietantes, como na qual a civilização ocidental está hoje mergulhada, poderão talvez favorecer as transformações necessárias para um modo de vida mais harmônico e mais justo.

Todo esforço dispendido no sentido da regularização do modo de convivência do homem ocidental passará inevitavelmente pela tentativa de reinvenção de um espaço crítico, central e cívico antes ocupado pela ágora, hoje fragmentado, substituído por uma tela de onde emergem as figuras inconsistentes dos líderes políticos com os quais o debate sobre as questões de ordem coletiva é inviável. A exemplo da cidade grega, cuja lei não permitia a ninguém a neutralidade política, sob pena de perda dos direitos de cidadania, é urgente a instituição de novas formas de participação política para que vozes até então ausentes do processo democrático sejam ouvidas. Baseadas no princípio da isegona, essas novas formas de cidadania deverão gerar uma razão política no maior número possível de cidadãos. Somente quando o político se tornar atributo de todos e cada cidadão estiver vinculado a algum grupo expressivo da sociedade, seja ele liberal, conservador, progressista ou reacionário, refletindo juntos os prós e contras a respeito de questões éticas e políticas básicas antes de decidir-se soberanamente, é que o funcionamento das democracias ocidentais encontrará estabilidade e realizará sua essência em plenitude, nessa cidade-mundo que a ciência e a técnica estão construindo.

A invenção de uma forma nova de existência coletiva melhor para todos, destinada a ultrapassar os interesses meramente individuais, a exemplo do que ocorreu nos primórdios de nossa civilização, será resultado do aguçamento da postura crítica dos cidadãos como um todo. A perplexidade, o questionamento rigoroso e sem limites, a liberdade de espírito, têm o incomensurável poder de desarticular os mais perversos mecanismos de manipulação dos indivíduos. Uma verdadeira democracia, mais propícia à excelência humana, apenas poderá ser vislumbrada por uma coletividade de homens esclarecidos, leitores e analistas competentes da complexidade dos fatos políticos e tecno-científicos, participantes incondicionais das querelas e controvérsias do presente, atentos às inestimáveis lições que a história da cultura ocidental pode oferecer através do diálogo permanente com o que há de mais radical em seu próprio passado, a herança dos gregos. 
SANTOS, M. C. A. dos. The Greeks and us. Trans/Form/Ação, São Paulo, v. 17, p. 133-141, 1994.

- ABSTRACT: This article gives an affirmative answer to the recurrent question concerning the effective contribution brought by the study of the political thought of the ancient Greeks to the problems faced by modern democratic societies.

- KEYWORDS: Ancient and modern democracy; paradigm; polis; paidéia; logos; philosophy.

\section{Referências bibliográficas}

1 ARENDT, H. Entre o passado e o futuro. São Paulo: Perspectiva, 1972.

2 BRÉHIER, E. Études d'ensemble. Paris: PUF, s.d.

3 CAVALCANTE, J. A pólis como quadro institucional da cultura grega. In: A democracia grega. Brasília: Universidade de Brasília, 1982.

4 COULANGES, F. La cité antique. Paris: Hachette, 1885.

5 EHRENBERG, V. L'etat gréc. Paris: Maspero, 1970.

6 FINLEY, M. Democracia antiga e moderna. Rio de Janeiro: Graal, 1985.

7 FINLEY, M., BAILEY, C. L'Hénitage de la Grèce et de Rome. Paris: R. Laffont, 1992.

8 HIRSCHAN, A. A retórica da intransigência. São Paulo: Companhia das Letras, 1992.

9 HORKHEIMER, M. Eclipse da razão. Rio de Janeiro: Labor, 1976.

10 JAEGER, W. Paideia. São Paulo: Herder, s.d.

11 SCHUHL, P. M. Études platoniciennes. Paris: PUF, 1960.

12 STRAUSS, L. Qu'est-ce que la philosophie et politique? Paris: PUF, 1959.

13 TUCIDIDES, Histoire de la guerre du Péloponnèse. Trad. de Romilly. Paris: R. Laffont, 1990.

14 VERNANT, J. P. Religions, histoires, raisons. Paris: Maspero, 1977.

15 . As origens do pensamento grego. São Paulo: Difel, 1981.

16 WOLFF, F. Filosofia grega e democracia. In: Discurso 14, São Paulo: Polis, 1983. 